\title{
JESUS DE NAZARÉ E OS ESTRANGEIROS
}

\author{
Luciano Manicardi ${ }^{1}$
}

\section{Premissa $^{2}$}

Algumas premissas são necessárias para o aprofundamento do tema. É muito difícil reconstruir a atitude que Jesus de Nazaré teve historicamente junto aos estrangeiros durante seu ministério. Entre a redação dos textos evangélicos e os acontecimentos há uma lacuna difícil a superar, porque os Evangelhos foram escritos quando a ideia de uma missão universal entre os gentios já tinha se consolidado e é compreensível que este estado de coisas tenha influenciado a memória histórica quanto à atitude de Jesus junto aos estrangeiros presente nos textos evangélicos ${ }^{3}$.

Além disso, é necessário levar em conta o quadro sociológico articulado e complexo da época de Jesus em relação aos "estrangeiros". O Antigo Testamento (AT) utiliza os termos zar (o estrangeiro em sentido étnico e político com uma conotação depreciativa) e nekar (aquele que pertence a um grupo étnico do qual Israel deve separar-se); quanto aos estrangeiros presentes em Israel, o AT distingue o nokri, o residente temporário, e o gher, o imigrante, o estrangeiro residente, aquele que vive no meio de um povo com que não tem relações de sangue. $\mathrm{O}$ Novo Testamento (NT) atesta a presença de prosélitos (Mt 23,15: os estrangeiros

\footnotetext{
Monge leigo da Comunidade de Bose. Magnano (BI), Itália.

Texto traduzido do italiano pela Equipe do CSEM.

3 Cf. MANICARDI, Ermenegildo. Gesù e gli stranieri. Ricerche Storico Bibliche, ano VIII, n. 1-2, 1996, p. 197-231. Este é o estudo mais recente e completo em relação ao nosso tema. Outras referências bibliográficas: JEREMIAS, Joachim. Jésus et les païens. Paris: Delachaux \& Niestlé, Neuchatel, 1956; VANHOOMISSEN, Guy. Dieu, son peuple et l'étranger. Bruxelles: Lumen Vitae, 2000, p. 52-60; TOMSON, Peter. Jésus et les auteurs du Nouveau Testament dans la relation au judaïsme. Paris: Cerf, 2003, p. 158-161. Para sublinhar a problematicidade da questão lembro que, de acordo com um estudioso como Sanders, o que se pode afirmar com segurança é apenas que "Jesus começou um movimento que chegou a considerar a missão para os gentios como uma lógica ampliação do próprio movimento" (SANDERS, Ed Parish. Gesù e il giudaismo. Genova: Marietti, 1992, p. 289). Conforme o mesmo autor "a tradição sobre Jesus teve que ser ampliada para colocá-lo em contato com os gentios" (p. 286) e "não é necessário pensar que Jesus tenha falado aos discípulos algo específico sobre os gentios" (p. 289).
} 
que se convertiam e aceitavam a Torá e a circuncisão), adoradores de Deus (At 18,7: pessoas de origem pagã que professavam a fé monoteísta, frequentavam a sinagoga, mas não se tornavam plenamente integrantes da comunidade judaica) e samaritanos (cf. Jo 4). Estes últimos, que são abertamente considerados estrangeiros em Lc 17,18, onde um samaritano é chamado alloghenés (um termo que nos LXX traduz o hebraico zar), ou seja, de "outra etnia", "estrangeiro", historicamente estavam em uma situação intermediária entre Israel e os estrangeiros: "Os samaritanos nunca foram tratados pura e simplesmente como estrangeiros, mas como um grupo de descendência duvidosa. Sua origem israelita não pode ser considerada como certa, mas também não pode ser descartada a priori. Sua filiação à comunidade de Israel, portanto, não é negada, mas apenas considerada duvidosa" (Emil Schürer). Por estes motivos, a situação no tempo de Jesus é tal que "torna pouco pertinente a utilização de uma definição sociológica formal e distinções nítidas que levem a uma determinação unívoca de quem é o estrangeiro na sociedade judaica do primeiro século" (Ermenegildo Manicardi).

Ademais, seria necessário também investigar cada Evangelho para distinguir as diferentes redações e detectar as distintas nuances da mensagem de todos os evangelistas sobre a relação entre Jesus e os estrangeiros, bem como discernir em cada texto o peso da tradição e o peso da redação. Parece-nos óbvio que isso não é possível neste ensaio. Como não é possível nos determos sobre todos os textos evangélicos que põem em relação, direta ou indiretamente, Jesus com estrangeiros (textos que começam em Mt 1, onde mulheres estrangeiras aparecem na genealogia de Jesus, e continuam em Mt 2, com os "magos" que chegam "do Oriente").

Após uma breve apresentação dos dados evangélicos sobre a relação vivida por Jesus com os estrangeiros, vamos realizar reflexões de corte hermenêutico a partir de encontros de Jesus com os estrangeiros e de palavras de Jesus sobre os estrangeiros.

\section{Jesus e os estrangeiros: uma visão de síntese}

Jesus limitou seu ministério e sua pregação ao território de Israel: "Eu não fui enviado senão às ovelhas perdidas da casa de Israel" (Mt 15,24). No entanto, os Evangelhos atestam a presença de estrangeiros entre as multidões que buscam Jesus (desde o início do seu ministério, conforme Mt 4,25; depois dos conflitos surgidos em Galileia, de acordo com Mc 3,8 e Lc 6,17). Se há estrangeiros que ouvem Jesus (oriundos principalmente da Decápole e da área em torno de Tiro e Sidônia), não há estrangeiros entre os Doze (cuja função está relacionada com as doze tribos de Israel): pode-se compreender a recusa de Jesus ao pedido do endemoninhado geraseno (Mc 5,1-20) para "ficar com ele" (Mc 5,18; cf. Mc 3,14). O encontro com o centurião de Cafarnaúm, em Mateus (8,5-13) apresenta a dificuldade do judeu Jesus para entrar na casa de um pagão (especialmente se a frase 8,7 deve ser 
entendida como uma interrogação: "Eu tenho que curá-lo depois de ir até você?"). Na redação de Lucas não há encontro direto entre Jesus e o centurião, mas tudo acontece através de mediadores judeus e o centurião é caracterizado como um adorador de Deus que ama o povo de Israel ("nosso povo" dizem os anciãos a Jesus) e que ajudou na construção da sinagoga (Lc 7,1-10). O encontro de Jesus em Caná da Galileia com um funcionário real, no IV evangelho (Jo 4,46-54), é parte de um conjunto extremamente teológico e simbólico que apresenta o encontro de Jesus com o judaísmo oficial (Nicodemos, Jo 3,1-21), com os samaritanos (a mulher samaritana: Jo 4,1-42) e com o mundo pagão (o funcionário real, um militar estrangeiro a serviço de Herodes Antipas: Jo 4,46-54). Além disso, nada no texto explicita ou focaliza o tema da estrangeiridade do interlocutor de Jesus. Os estrangeiros que tentam ver Jesus em Jerusalém são, provavelmente, gregos de nascimento (éllenes) que se aproximaram ao judaísmo através de contactos com os judeus da diáspora (Jo 12,20 -21): a vinda deles permite que Jesus explicite que o plano de salvação de Deus e sua missão de conduzir também as ovelhas que são de outro redil $(J o$ 10,16) serão cumpridos no evento da elevação quando Jesus "atrairá todos a si" (Jo 12,32). "A plena integração dos estrangeiros na salvação de Jesus só ocorrerá após a Páscoa" (Ermenegildo Manicardi).

Em suas andanças Jesus entra em territórios estrangeiros onde encontra pessoas que são abertamente apresentadas como estrangeiras (Mc 7,24-30; Mt 15,21-28) ou assim supostas (Mc 7,31-37). Se Mateus relata o mandato missionário de Jesus aos seus discípulos que exclui da sua ação "gentios" e "samaritanos" (Mt 10,5-6: "não deveis ir aos territórios dos pagãos, nem entrar nas cidades dos samaritanos. Ide, antes, às ovelhas perdidas casa de Israel"), Lucas e João apresentam significativos encontros de Jesus com os samaritanos (LC 17,11-19; Jo 4,1-42): elemento típico destes encontros é que sempre ocorrem em território samaritano, onde Jesus está apenas de passagem.

Em resumo, Jesus, como profeta e na esteira dos profetas do Antigo Testamento, dirigiu sua mensagem e sua pregação ao povo de Israel, tendo em vista sua conversão, mas também anunciou a colheita final dos gentios e sua inclusão escatológica na salvação, recuperando a mensagem profética sobre a vinda escatológica dos povos ao monte de Deus (Is 2,2-5; 56,7-8; Mq 4,1-4) e sobre o banquete preparado por Deus para todos os povos (Is 25, 6-7): Mt 8,11-12; 22,1-10; Lc 14,15-24 (cf. também Mt 24,31; 25,31-32; Mc 13,27). Jesus esperou e anunciou a incorporação dos gentios no reino de Deus "como um ato escatológico do poder de Deus, como a última grande revelação da graça de Deus" (Joachim Jeremias). Esta visão em relação aos pagãos não isolava Jesus no panorama do judaísmo do seu tempo, como se este nutrisse apenas a ideia da destruição final dos gentios por parte de Deus ${ }^{4}$, porque a ideia de uma admissão

${ }^{4}$ Cf. RICHES, John. Jesus and the Transformation of Judaism. New York: Seabury, 1982. 
dos gentios ao Reino nos últimos tempos era atestada e recorrente ${ }^{5}$, embora, é claro, ao lado de outras abordagens com diferente enfoque.

\section{Pistas hermenêuticas}

$\mathrm{O}$ encontro de Jesus com uma mulher estrangeira (cananeia em Mt 15,21-18; siro-fenícia em Mc 7,24-30) mostra que ele, ou melhor, eles (Jesus é estrangeiro para a mulher, assim como a mulher o é para Jesus) tiveram que superar muitas barreiras para chegarem a um entendimento. Marcos parece multiplicar os elementos de diversidade da mulher: a diferença de gênero, a estrangeiridade, talvez o status socioeconômico (de acordo com Theissen a mulher pertence à camada social elevada e rica de gregos urbanizados que vivem na área fronteiriça de Tiro e na Galileia, com os quais estavam em conflito os camponeses pobres judeus, cujo trabalho agrícola também servia para sustentar os habitantes da cidade), talvez até mesmo uma distância moral (o termo "siro-fenícia" tinha, na sátira latina, a conotação de mulher pouco recomendável, prostituta). E, finalmente, e acima de tudo, a diferença linguística: "era grega". Ellenís (grega) indica a pertença linguístico-cultural (enquanto syrophoiníkissa designa a linhagem e a religião pagã). Eles conversam: em que língua? Quem fala a língua do outro? Jesus fala grego? Ou a mulher fala aramaico? De qualquer forma, deve ter havido a adaptação recíproca à língua do outro, o esforço de abandonar a língua nativa para se expressar no idioma acessível ao outro.

Acima de tudo, a posição rigorosamente "judaica" de Jesus põe muitas dificuldades a esta estrangeira: a redação de Mateus mostra um longo e obstinado iter da mulher que se choca com o silêncio de Jesus (Mt 15,23), com a resposta seca aos discípulos que se tornam intercessores em favor da mulher ("Eu não fui enviado senão às ovelhas perdidas da casa de Israel": Mt 15,24), com a dura resposta dirigida diretamente a ela (Mt 15,26). A razão subjacente que separa Jesus da estrangeira é expressa por Mc 7,27 ("Deixe que primeiro os filhos se saciem...") nos termos teológicos que evocam os tempos do desenvolvimento do plano de Deus: primeiro os judeus, depois os gregos. Estamos diante de uma concepção teológica muito difundida na igreja primitiva sobre o projeto salvífico de Deus: a história da salvação possui um desenvolvimento próprio, um plano específico que não pode ser desestruturado. A obstinação da mulher, que acolhe as palavras de Jesus e desloca o foco do plano temporal para o plano espacial ("os cachorrinhos debaixo da mesa": Mc 7,28), muda a atitude de Jesus. E isso tem duas implicações.

Em primeiro lugar, Jesus deixa-se desafiar e transformar pelo sofrimento que move a mulher e lhe dá coragem e determinação. Sua filha doente é uma razão mais do que suficiente para não desistir de pedir, e Jesus ouve o sofrimento

5 Cf. SANDERS, op. cit., p. 277-289. 
da mulher estrangeira. Assim como ouve o sofrimento do endemoninhado geraseno (não se afasta diante de suas invectivas, mas fica e conversa com ele, tratando-o como um ser humano: Mc 5,1-20) e acolhe o centurião pagão que vai ao seu encontro trazendo o sofrimento de seu servo (Mt 8,6: "o meu criado está deitado em casa paralítico, sofrendo dores atrozes"): a experiência universal do sofrimento reflete aquela fragilidade do humano que Jesus ouve e que o leva a se aproximar (farsi prossimo) do outro, embora estrangeiro. A parábola do Bom Samaritano mostra que a compaixão cria proximidade: se a ideia de próximo, na origem, indica o compatriota, a parábola de Lc 10,30-37 mostra que os estrangeiros podem se tornar parte de uma única pátria a partir da maneira como lidam com o sofrimento do outro. A presença do sofredor é um chamado para eu me tornar seu próximo, seu "compatriota", para fazer, do meu residir no território do sofrimento (território que geralmente isola e separa), uma oportunidade de relacionamento e justiça.

Em segundo lugar, essa escuta do sofrimento do outro (ou do sofrimento que o outro padece por causa de uma pessoa por ele amada) se torna capaz de corrigir uma visão teológica correta, mas abstrata, da história da salvação, em uma mais concreta práxis de salvação das histórias; começando pelas histórias pessoais e familiares, sempre precárias e sempre marcadas por dramas e sofrimentos. Encaixando-se na visão dos tempos da salvação de Jesus, a mulher introduz a metáfora espacial da casa e da mesa onde "os cachorros domésticos" acesso junto aos filhos e se alimentam com as migalhas dos filhos, os legítimos comensais. O cachorros e os filhos, os não-judeus e os judeus têm uma única casa e uma única mesa. A observação genial da mulher converte e dá plenitude à visão de Jesus: na única casa e ao redor da única mesa há possibilidade de uma contemporaneidade da refeição entre filhos de Israel e estrangeiros, uma contemporaneidade em que a primazia de Israel é reconhecida e, ao mesmo tempo, redimensionada.

Neste, como em outros casos, Jesus consegue reconhecer a fé do outro, do estrangeiro, do não-hebreu (Lc 7,9; 17,19; Mt 8,13; 15,28): isto também pressupõe o reconhecimento implícito da bondade do caminho espiritual que esse estrangeiro realizou a partir de sua própria cultura. A admiração de Jesus ao constatar a fé do estrangeiro ("Eu vos digo que nem mesmo em Israel encontrei tamanha fé": Lc 7,9; "mulher, grande é a tua fé": Mt 15,28) é significativa: a pertença judaica, o "orgulho hebreu" de Jesus o leva a encontrar o estrangeiro a partir de uma identidade sólida, mas também aberta, não fixa, não engessada em nacionalismos ou chauvinismos. A sua pertença nunca é declinada de forma fechada e excludente, e isso porque fica claro, para ele, que as diferenças étnicas

6 Desta maneira, e não como "cachorrinhos", deve ser entendido o grego tà kynária de Mc 7,27.28; Mt 15,26.27. Cf. BAUDOZ, Jean-François. Les miettes de la table. Étude synoptique et socioreligieuse de Mt 15,21-28 et de Mc 7,24-30. Paris: Gabalda, 1995, p. 258-265. 
não ofuscam, mas honram o rosto do Deus da promessa que foi feita um tempo a Abraão (Gn 12,1-3; cf. Mt 8, 11). Jesus não nega ou minimiza as diferenças dos estrangeiros, mas as acolhe focalizando a positividade dos próprios estrangeiros: a capacidade de ação de graças (Lc 17,18); a aceitação do plano salvífico do Deus de Israel (Mc 7,28); a fé em Jesus e a confiança radical nele e na sua palavra (Mt 8,8).

De fato, quando Jesus não é acolhido na aldeia samaritana (Lc 9,51-56), reprova com dureza a lógica perversa da retaliação em que caem imediatamente seus discípulos pedindo uma punição exemplar: ele permanece fiel à força de sua mensagem, pagando o preço até o fim, sem nunca ceder à tentação da violência na relação com o outro que se apresenta como hostil. Jesus não impõe reciprocidade, não exige que seu comportamento seja assumido pelos outros, mas acolhe a hostilidade sem responder ao mal com o mal. Jesus não transforma o estrangeiro em inimigo, pelo contrário, como mostra o episódio do encontro com a mulher samaritana, ele se empenha para fazer do inimigo um amigo.

O conto de Jo 4 é a história da criação de uma relação entre dois membros de grupos humanos entre os quais havia incomunicabilidade: "Os judeus não se relacionam com os samaritanos" (Jo 4,9); é a história de um encontro que acontece a partir de uma inicial inimizade categorial que separa sem qualquer possibilidade de reconciliação "nós" e "vós"; é a história da conversão de uma alteridade inimiga para uma alteridade amiga. A dinâmica deste encontro é interessante. Quando a identidade de uma pessoa está totalmente desapropriada na sua pertença étnica (e/ou religiosa), o outro não é mais um rosto, um nome, uma história e um desejo, mas simplesmente o membro de uma entidade diferente e, por conseguinte, inimiga: "você é judeu, eu uma mulher samaritana" (Jo 4,9). O encontro pode acontecer a partir de uma sede comum: a mulher foi tirar água, Jesus pede para beber. $\mathrm{O}$ encontro pode começar pelo ato de coragem pelo qual uma pessoa ousa manifestar as próprias necessidades, expõe-se ao outro em sua pobreza, em sua vulnerabilidade, faz do outro a pessoa que pode ajudá-lo: "Dá-me de beber" (Jo 4,7). Jesus vence a distância direcionando a palavra para a mulher: este risco cria a premissa do diálogo, que começa quando a mulher é apanhada de surpresa por este fato inesperado: não há nenhum comportamento em Jesus que reflita os preconceitos que os judeus tinham para com os samaritanos. Jesus "ousa" quebrar o hábito e a preguiça dos rótulos e dos estereótipos que fazem do outro uma categoria e não uma pessoa. Acolhida, a samaritana mostra confiança em Jesus "ousando" sua própria pobreza diante dele e perguntando algo: agora é ela que pede a Jesus de beber (Jo 4,15). Estabelecida a confiança recíproca, Jesus conduz a mulher para sua história pessoal e familiar, para seu passado (Jo 4,16-18): ao não se sentir desprezada na sua história conturbada, a mulher pode expor sua diversidade religiosa em relação ao judeu Jesus (Jo 4,19-20). E Jesus não estigmatiza nem condena, mas interpreta tanto os judeus quanto os samaritanos, 
"nós" e "vós", à luz do Terceiro, o Reino de Deus, do Deus que é de ambos (Jo 4,21-24). Destarte ocorre o encontro: e, talvez, a verdadeira sede é a sede do encontro (conforme o conto, nem a mulher tira água nem Jesus bebe). Jesus se doa como Messias e a mulher, e os samaritanos com ela, confiam em Jesus e acreditam nele como o salvador do mundo (Jo 4,39-42).

Assim como acontece com a mulher samaritana (Jo 4,9), diante de Pilatos também Jesus não se deixa enjaular em uma identificação étnica (Jo 18,35), e diante do procurador da Judeia reivindica que seu reino "não é deste mundo" (Jo 18,36). E quando é identificado e "insultado" como sendo um estrangeiro ("és samaritano": Jo 8,48), nem sequer se digna responder à acusação. Evidentemente, a sua visão dos samaritanos e, mais em geral, dos estrangeiros não é a mesma de seus acusadores.

O valor revelador do estrangeiro é sublinhado por Jesus no discurso sobre o juízo final no primeiro Evangelho: "Eu era forasteiro e me recebestes em casa" (Mt 25,35 cf. também v. 43). Nesse texto a humanidade toda está sujeita à autoridade dos fracos, incluindo os estrangeiros. A relação com o estrangeiro aparece como um item do juízo escatológico.

Aliás, não só por trás de cada estrangeiro se faz presente a figura de Cristo, mas, de acordo com o IV evangelho, Jesus revela o Pai como estrangeiro: para João a estrangeiridade é categoria de revelação. Jesus levanta aquelas questões que surgem geralmente na frente de um estrangeiro: "De onde é?"; "Que língua fala?". Aqueles que simplesmente acham que Jesus vem de Nazaré (Jo 1,45-46), da Galileia (Jo 7,41), têm que entender que Jesus vem do alto, de Deus, do céu, do Pai (Jo 3,31; 8.23; 16,28.30); Jesus falava aramaico como seus interlocutores, mas na verdade ele fala as palavras de Deus (Jo 3,34). Nesta visão teológica Jesus aparece estrangeiro também para seus compatriotas e coloca cada ser humano diante do necessário salto da fé, da passagem naquele território da fé onde não são mais importantes as fronteiras das pátrias e as pertenças étnicas, mas a acolhida do "dom de Deus" (Jo 4,10) em Cristo Jesus. 